\title{
Using a combined bio-ecological and capability perspective to understand inclusive education in South Africa
}

\author{
Anwynne Kern ${ }^{1}$
}

Accepted: 2 October 2021 / Published online: 27 January 2022

(C) The Author(s) 2021

\begin{abstract}
Inclusive educational practices have been adopted worldwide to address inequalities endemic to education systems. In South Africa, the process toward inclusion commenced in October 1996 and was realized in 2001 with the Education White Paper 6. However, the implementation of inclusion in South Africa has been marred by challenges. These challenges have largely been examined through an ecosystemic theoretical lens offering insight into the contextual challenges facing inclusion but does not adequately explore the role that the person involved in the implementation and their specific dispositions play in the enactment of inclusion. This article argues that, to better understand the challenges individuals face with implementing inclusion, a broader lens integrating bioecological theory and the capability approach is needed. This integration highlights the need to look at a complexity of issues to understand what is valued, as competing values, and the choices between these will influence the implementation of inclusion.
\end{abstract}

Keywords Bio-ecological theory $\cdot$ Capability approach $\cdot$ Education $\cdot$ Inclusion

According to the World Health Organization (WHO, 2015), 20 percent of children in any schooling system could be considered to be experiencing some form of barrier to learning such as poverty, abuse, language, and disability. In South Africa, it is reported that, of the 5.8 percent of children identified as having disabilities, only 1.01 percent of these children are enrolled in mainstream education, with a total of 1.3 percent of children enrolled in

This work was supported by the National Institute for Human and Social Sciences (NIHSS) under Grant number SDS15/1037 and National Research Fund (NRF) under Grant number NFSG180417321950. I am grateful to Professors Sumaya Laher and Elizabeth Walton for the support provided.

Anwynne Kern

Anwynne.kern@wits.ac.za

1 University of the Witwatersrand, Gauteng, Umthombo Building, East Campus, 1 Jan Smuts Avenue, Braamfontein, Johannesburg 2000, South Africa 
mainstream education in the Gauteng Province (DoBE, 2015). These figures indicate that, as a country, South Africa is experiencing difficulty implementing inclusion. Difficulties with the implementation of inclusion have been identified in numerous articles (DoBE, 2015; Donohue \& Bornman, 2014; Themane \& Thobejane, 2018) and are typically understood from an ecosystemic theoretical lens (Abery et al., 2017; Davison \& Scholl, 2017; Hackett et al., 2016; Kamenopoulou, 2016). An ecosystemic lens, with its ability to study relationships and connections between influential factors within environments (Anderson et al., 2014), offers insight into the contextual difficulties facing inclusion and was therefore used to identify challenges to inclusion because the policy of inclusion in South Africa has adopted an ecosystemic perspective (Engelbrecht, 2020). This perspective moves away from locating barriers to learning within the child to locating them within the macro-, meso-, and micro-systems that prevent access to education (Du Plessis, 2013; Engelbrecht, 2020; Potgieter-Groot et al., 2012; Swart \& Pettipher, 2016).

South Africa has several policies related to inclusion such as the Education White Paper 6 (EWP6) and the Policy on Screening Identification and Assessment; however, the support that these policies generate among those affected determine its success or failure. Cognizance therefore needs to be taken of the individuals tasked with the implementation of inclusion, along with their contexts. These include district officials, principals, teachers, and parents. This consideration is important given that the EWP6 (Department of Education [DoE] 2001, p. 33) states that "public awareness and acceptance of inclusion will be essential for the establishment of an inclusive society and the inclusive education and training system". The education ministry explains that it aims to win the support of "national actors and role-players" and to review their "rights, responsibilities and obligations" (DoE, 2001, p. 33). Thus, the agency and capacity of individuals cannot be overlooked with regards to policy and its subsequent implementation (Du Plessis, 2013). Furthermore, the successful implementation of inclusion is highly dependent on various role-players such as parents and teachers. Responsibility and obligations infer action on the part of role-players. However, the various factors that influence the "role-player's" ability to "act" need to be explored in further depth (Anderson et al., 2014) to determine if they are, in fact, capable of fulfilling the responsibilities and obligations assigned to them.

Consequently, in this article I argue that bio-ecological theory (BET), with its focus on factors working in the present and how these factors affect an individual's future (Bronfenbrenner \& Evans, 2000), and the capability approach (CA), with its "agent-oriented view" (Sen, 1999, p. 281) could be used complementarily to understand some of the challenges inherent in the implementation of inclusion. Furthermore, BET and the CA offer insight into the individual characteristics that may affect the implementation of inclusion and how these characteristics are impacted by the individual's particular context. This focus on the individuals responsible for the implementation of inclusion contrasts with the policy understanding of inclusion in South Africa, which is context- and systems-focused, with the DoBE $(2015$, p. 7) stating that inclusive education is about the "transformation of an education system . . . into one integrated system". A focus on the individual is, however, aligned with Allan (2005) who asserts that inclusion is something that we do to ourselves and not something that we do to others.

Given that this article aims to present a conceptual framework that integrates BET and the CA, I reviewed relevant research reports and studies, with the aim of explaining BET and the CA and how they have been used in understanding and supporting education - more specifically, inclusion in education. This understanding would lead to an identification of the limitations of the theories with regards to inclusion (Xiao \& Watson, 2019) on which the conceptual framework was built. Keywords used to identify relevant literature 
were "bio-ecological theory", “capability approach", "education", "inclusive education", and "inclusion".

As inclusion is contextually specific, a short description of inclusion, with a focus on South Africa, is provided, followed by an overview and critique of BET and the CA. Subsequently, the manner in which the two theories complement each other is presented in a conceptual framework, developed by the author, to increase the understanding of factors affecting individuals' support for inclusion.

\section{What is inclusion?}

Inclusion is a complex concept, with numerous interpretations (Anderson et al., 2014; Artiles et al., 2006; Brantlinger, 2003; Göransson \& Nilholm, 2014; Reindal, 2016; Slee, 2011; Thomazet, 2009). While the concept is used in various contexts, inclusion is a term often used in the educational environment.

In South Africa, inclusion in education was developed within the broader political, social, and cultural landscape. As a result, inclusion is aligned with the Constitution and is aimed at advancing human rights and freedoms, equality, and dignity (Andrews et al., 2019; Engelbrecht, 2020). The focus of inclusion is thus about equity, access, full participation, and quality of learning (Engelbrecht \& Muthukrishna, 2019). This alignment with the Constitution, and its subsequent focus, in conjunction with the language used in the policy documents related to inclusion in education in South Africa, led the author to adopt Reindal's community definition of inclusion (DoE, 2001; Engelbrecht, 2006; Yssel et al., 2007). This definition states that inclusion is a way of creating communities with "specific characteristics" (Reindal, 2016, p. 4) of equity, care, justice, and value for diversity. The EWP6 states that it hopes that inclusive education would provide "a cornerstone of an integrated and caring society" (DoE, 2001, p. 10) where negative stereotypes are uncovered and unconditional acceptance promoted. This is echoed by UNESCO (1994, p. ix), which describes a school as a microcosm of society, with the implementation of inclusion viewed as the "the most effective means of combating discriminatory attitudes, creating welcoming communities, building an inclusive society and achieving education for all". Thus, while the outcomes of inclusion are felt across communities, its implementation rests on individuals.

Okkolin et al. (2018) discuss Kuippis and Hausstatter's three discourses of inclusive education. The first relates to the inclusion of people with disabilities. The second, while articulating a need to address issues of access, participation, and achievement, directing inclusive education to all, "focuses on certain populations considered the most vulnerable and marginalized" (Okkolin et al., 2018, p. 423). Heterogeneity is emphasized in the third discourse, with diversity becoming the "starting point for educational theory and practice" (Okkolin et al., 2018, p. 423). While diversity and the acknowledgment thereof are fundamental to inclusion, inclusion in South Africa appears to be aligned within the second discourse. This responds to the exclusionary practices associated with the country's history and the subsequent focus on ensuring that all children, principally those who are from marginalized and underprivileged or disenfranchised backgrounds, have access to quality education.

With regards to the school environment, inclusion refers to the education of all children, including those with disabilities, in mainstream classrooms with their peers (WHO, 2011). In so doing, a focus is on whole-school change as opposed to a focus on the individual 
child. This is aligned with the understanding of inclusion in South Africa which is "a process of addressing the diverse needs of all learners by reducing barriers to, and within the learning environment" (DoE, 2020). To reduce barriers to learning, the manner in which barriers prevent children from accessing, participating in, and succeeding in education needs to be identified (Slee, 2011). Barriers are thus understood as possibly emerging from within the individual in the form of disabilities; however, barriers are also understood to emerge from within the education system, as well as socioeconomic factors and life experiences (DoBE, 2018; DoE, 2001).

Equality and equity are both underscored in the policy documents on inclusion in education in South Africa (DoE, 2001; Republic of South Africa, 1996), resulting in the redistribution of resources based on these characteristics (Sayed \& Motala, 2012). The policy documents refer to equality in education, which implies sameness and nondiscrimination (Sayed \& Motala, 2012) given the historically rampant discrimination evidenced in the country's policies. However, inclusion in education is also a social-justice issue and thus links to equity, which means "the quality of being equal and fair" (Unterhalter, 2009, p. 416). In this regard, an unequal distribution of resources and differentiation may be needed as Wrigley et al. (2012) argue that an equitable distribution of resources is needed to see meaningful change. South Africa, with its quintile system, aims to be more equitable, with poorer schools receiving a greater percentage of funds per child compared to their richer counterparts.

Based on the aforementioned, inclusion in South Africa is focused on the changes that need to take place within the systems in order to support individual children. However, while it is acknowledged that individuals are responsible for the implementation of inclusion, these individuals are not prioritized and placed at the center of the systems. Instead, with inclusive education being located within the ecological systems theory, the learner (and not the implementer of the policy) is placed at the center of the system (Anderson et al., 2014). Bronfenbrenner's BET and its use in inclusive education in South Africa is discussed below.

\section{Bio-ecological theory (BET)}

Bronfenbrenner's theory of human development underwent considerable change from its introduction, as the ecological systems theory in the 1970s, to the emergence of BET of human development in 2007 (Anderson et al., 2014). The theory reflects developmental and systemic dimensions (Smit et al., 2020) aimed at understanding the influence that the "forces operating in the present had on the development of an individual in the future" (Bronfenbrenner \& Evans, 2000, p. 117).

Within BET, the individual is viewed as influencing and being influenced by the environment through feedback loops. When feedback gives rise to a change in the system, it is referred to as positive feedback, while no change is referred to as negative feedback. Thus, negative and positive feedback are associated with creating, respectively, stability and change within the system. The introduction of the EWP6 would be considered positive feedback since it signalled major changes in the education system; however, these changes did not necessarily translate to changes in the individual and their abilities to implement inclusion. While the system instituted an inclusive policy, and mandated training (DoE, 2001), not all teachers feel equipped to teach learners with barriers (Dalton et al., 2012; De Boer et al., 2011; DoBE, 2015; Engelbrecht, 2020), nor do parents know what is required of them (Kern, 2020). Consequently, the individuals 
who are identified as integral to the success of inclusion (DoE, 2001) find themselves in a system that has received positive feedback while, as individuals, they are in a state of negative feedback.

Unlike the ecological theory, with its nested structures that demonstrate the influence of context, BET posits that the context is only one dimension that affects development. The mature version of the theory consists of four dimensions: (1) process; (2) person; (3) context; and (4) time. While the four dimensions influence development simultaneously, the process dimension is central to the theory, as can be viewed in the author's model of the theory captured in Figure 1 below.

The following is a broad-level overview of the four dimensions of the theory and their interactions, which are presented in Figure 1. At the center of the model are the four interacting dimensions, with the process dimension of the theory situated centrally. According to Bronfenbrenner \& Morris (2007), the process dimension captures the dual interactions that occur between the person and the context across time. The process dimension comprises proximal processes, which refer to specific interactions that occur between the individual and people, objects or symbols (Bronfenbrenner \& Morris, 2007) and impacts human development, directly or indirectly (Smit et al., 2020). To facilitate development, the proximal processes must occur regularly over time and must increase in complexity. Within inclusion, the interactions that take place between the role-players themselves, their environments, and the various education departments constitute the proximal processes. These interactions are influenced by the individual's personal characteristics and occur within and across contexts as well as across time.

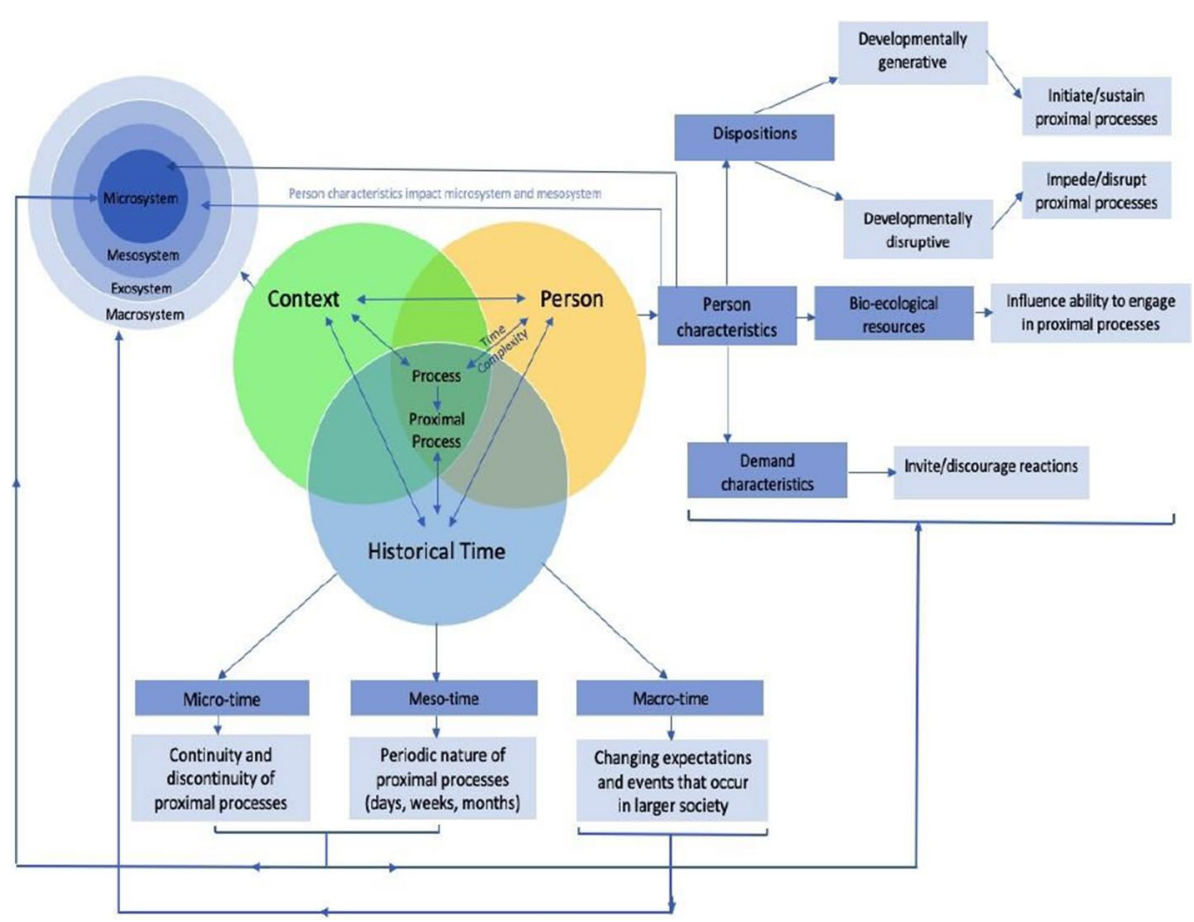

Figure 1 The bio-ecological model 
While the EWP6 outlines the department's responsibility to educate society, it is evident that this knowledge has not been imparted to teachers (Engelbrecht, 2020; Lui et al., 2015). Given that teachers, who are at the forefront of implementing inclusion, lack knowledge of inclusion (Engelbrecht, 2020; Seedat, 2018), it is assumed that parents are also unfamiliar with it (Kern, 2020). A conclusion could therefore be drawn that the proximal processes between parents, teachers, and other role-players have not been sufficient to develop their understanding of inclusion. In addition, research (Singh \& Mbokodi, 2011) has shown that parents are not always at ease with communicating with the school, which hinders the proximal process between parents and the school. Thus, an understanding of proximal processes may provide much-needed insight into the nature of interactions that occur between various role-players and how these may facilitate or hinder inclusion.

The person dimension refers to the biologically based person characteristics of an individual (Rosa \& Tudge, 2013). By influencing the direction and power of proximal processes, the person dimension is instrumental in shaping the course of future development. The person characteristics are a product of development but also produce development through their ability to set proximal processes in motion and sustain them. Person characteristics comprise three components that refer to dispositions, which are developmentally generative or developmentally disruptive biological resources that influence an individual's ability to engage in proximal processes and demand characteristics that serve to invite or discourage interactions with others (Bronfenbrenner \& Morris, 2007; Rosa \& Tudge, 2013). Person characteristics have the potential to influence an individual's ability to implement inclusion as they comprise characteristics, such as distractibility, shyness, responsiveness, knowledge, skills, and experience, to name a few. However, these dispositions, ecological resources, and demand characteristics are not considered when evaluating the factors influencing the implementation of inclusion.

The person characteristics influence the interactions that occur in the micro-system and meso-system and are, in turn, impacted by micro-time and meso-time, which refers to the continuity of proximal processes and their occurrence over time, respectively (Bronfenbrenner \& Morris, 2007; Rosa \& Tudge, 2013). With regards to inclusion, the person characteristics of teachers, principals, and district officials impact the nature of the interaction with the individuals at the center of the system, for example, parents, thereby impacting the proximal processes that occur between the parents and the micro-system and meso-system. Examples of parental person characteristics that impact proximal processes include language and parents' levels of education (De Boer et al., 2011). However, while BET identifies that the person characteristics impact development, it does not account for how or why these characteristics are employed or not. This means that how the person is able to mobilize their person characteristics to assist in their well-being and development is not explained within the theory but is important to understand if insight into the factors affecting inclusion are to be better understood.

The context dimension refers to a set of four nested structures that reciprocally influence other structures. The micro-system refers to the patterns of immediate interactions and settings that have contact with the developing individual. It usually refers to friends, family, and teachers. The meso-system refers to the relationships that exist between the individual settings found in the micro-system. Examples are interactions between teachers and parents and between therapists and teachers/parents. The exo-system refers to settings that have an influence, directly or indirectly, on the developing individual but which do not interact directly with the individual. Examples of these systems are school management boards and parents' workplaces. Lastly, the macro-system refers to the cultural world surrounding the developing individual and includes beliefs, ideologies, customs, traditions, 
and policies (Bronfenbrenner, 1977; Landsberg et al., 2005; Rosa \& Tudge, 2013). Specifically, apartheid would be found in the macro-system; similarly, inclusion and its policies are also located within this system. The influence of the macro-system on individuals, in terms of the development of their values and beliefs, contributes to an understanding of their support for inclusion.

The last dimension of BET is time, both ontogenetic and historical time, which is presented at three successive levels, i.e. micro-time, meso-time, and macro-time (Bronfenbrenner \& Morris, 2007; Rosa \& Tudge, 2013). Micro-time and meso-time impact the interactions that occur in the micro-system. Macro-time, which refers to changing expectations and events that occur in larger society and within and across generations, influences the macro-system. Macro-time has played a major role in the development of inclusion in South Africa; the changing expectations of individuals across macro-time may have been one of the driving forces toward inclusion.

A limitation with this theory in relation to explaining the adoption of inclusion is that it does not explain how individuals use their person characteristics to promote their development. In addition, the challenges that arise when resources are and are not available is not understood. Based on the theory, it can be assumed that, with the requisite training, an individual will shift toward being inclusive, i.e. they will act in a way to support the implementation of inclusion. However, this theory does not take cognizance of the individual's freedom and agency which impacts the individual's move toward and support for inclusion. This criticism is mirrored by Phasha et al. (2017), who argue that BET does not address issues of power and identity. Houston (2017) expands on the issue of power to include the limited way agency and structure are understood as shaping the "person-context" interrelationship.

Additionally, BET has been criticized for the way it addresses culture. Vélez-Agosto et al. (2017) argue that culture is a product of human activity and is thus not separate from the individual. It should therefore not be placed in the macro-system but within the microsystem where it plays a role in everyday activities. Understanding an individual's support for inclusion in South Africa, with its diversity of cultures, therefore becomes more nuanced when one considers that the individual's culture will affect their proximal processes within the micro-systems.

BET could also be criticized for its focus on the child and their characteristics given that inclusion necessitates a move away from the child experiencing the barrier to learning (Anderson et al., 2014, p. 5). This shift to the focus on the child and their characteristics is opposed to the understanding of inclusion, which seeks to address barriers within the system. However, individuals do impact the implementation of inclusion. Perhaps an argument could be presented that the individual at the center need not be the child, and perhaps factors affecting the implementation of inclusion could be better understood if the individuals/stakeholders tasked with the responsibility of implementing inclusion are placed at the centre.

\section{Capability approach (CA)}

The CA, developed by Amartya Sen and Martha Nussbaum, is a framework used to assess individual well-being and social arrangements. Its consideration of heterogeneity, in terms of "personal characteristics, external circumstances, inter-individual variations . . . and inter-end variations" (Terzi, 2005, p. 205), draws parallels with the third discourse on inclusive education (Okkolin et al., 2018) and highlights a consideration for equality and justice (Dalkilic \& Vadeboncoeur, 2016; Terzi, 2005). In this way, the CA could be used to explain inclusion. The consideration is made when determining the level of provision 
of resources required by individual children in order to attain specific capabilities. In so doing, the child's "capability to be educated" is enhanced.

The CA comprises three fundamental concepts: (1) functionings; (2) capabilities; and (3) agency (Deneulin \& McGregor, 2010; Robeyns, 2005). At its core, however, is a focus on what people are able to do and be, i.e. their capabilities, while recognizing that social and environmental structures influence an individual's ability to convert resources into functionings. Within the educational setting, functionings refer to the "beings and doings" a child has achieved such as "access to and participation in education, learning and achievement" (Okkolin et al., 2018, pp. 424-425). Both Sen and Nussbaum consider "being educated" an essential capability (Okkolin et al., 2018) with inclusive education promoting the development of capabilities (Terzi, 2005). Although capabilities are at the core of the approach, as you will see in the author's figure below, the conceptualization of the approach starts with resources (Fig. 2).

Within the CA, resources have value since they provide an individual with the opportunity to develop capabilities (Deneulin \& McGregor, 2010). The availability of resources is also important for successful inclusion (Andrews et al., 2019; Engelbrecht, 2020). These refer to human resources, physical resources, financial resources, and knowledge, and are also referred to as goods or commodities (Crocker \& Robeyns, 2010; Robeyns, 2005). However, as the CA argues, access to resources does not equate to capabilities and functionings, in this case, being inclusive. Instead, what a person is able to do with the resource determines the outcome and what a person is able to do is affected by the individual's personal, social, and environmental conversion factors (Robeyns, 2005). However, while the CA addresses what a person is able to do, it does not account for the role of the individual's innate factors, referred to as "person characteristics" in BET. So, while an individual may have access to training and development (a resource) with regards to inclusion, their personal characteristics, e.g., being distractible or curious, mean that they walk away from the training with different levels of knowledge. Thus, the personal characteristic in conjunction with the conversion factors influences the attainment of a functioning.

The conversion factors, which influence the ability to develop capabilities, are affected by what the individual is able to do given the opportunity and choice. This equates to freedom that is, however, impacted by the macro-system of the individual. In environments where disability or difference are viewed as witchcraft, individuals may not have the freedom to act inclusively based on the cultural beliefs of the community. Alternatively, a school environment, in terms of policies and practices, may prohibit a teacher from implementing inclusion, thereby inhibiting the teacher's freedom. It is therefore important to note that conversion factors can act to promote or hinder inclusion (Trani et al., 2011).

Capabilities also refer to an individual's ability to pursue and participate in activities that they consider valuable (Claassen, 2014; Tikly \& Barrett, 2011; Walker, 2012). The notion of value emerges in the explanation of capabilities and functionings that indicate that the activities and skills that people pursue are driven by the value that has been attached to them. However, the question is whether the capabilities or functionings being pursued are valued as a means to an end, or as an end in themselves (Okkolin et al., 2018). For example, is being educated valued because it is a means to acquire specific skills (e.g., the ability to read or do everyday math) (an end) or is it valued because it gives a person the opportunity to pursue a better life (a means)?

Value is expressed through the individual's agency, which refers to the individual's ability to choose what they do or can do to achieve a specific outcome (Crocker \& Robeyns, 2010). Consequently, a capability, which refers to a possible achievement, is only converted into a realized achievement, i.e. a functioning, if the individual values the functioning and 


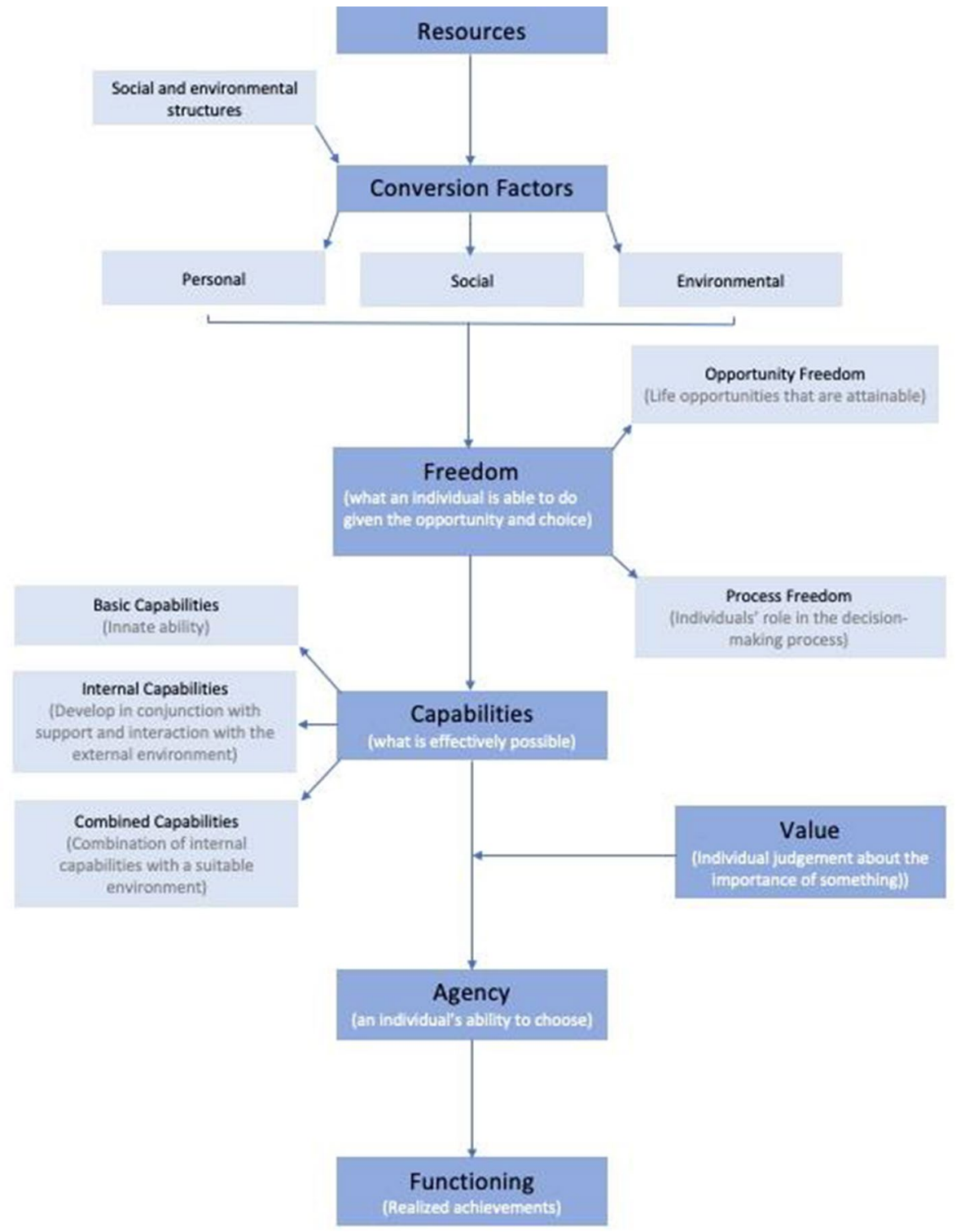

Figure 2 The capability approach

expresses their agency in their attainment of specific functionings. In relation to inclusion, the CA would argue that individuals will aim to attain inclusion if they value it and have the freedom to pursue it. Given the history of South Africa, inclusion is embedded in the Constitution and the education policy documents. However, this value is ascribed by external parties. What is not investigated is to what extent the individuals responsible for implementing inclusion value it, and whether they have the resources, conversion factors, and freedom to seek out what they value. 
This is linked to Sen's idea of "adaptive preferences" (Otto \& Ziegler, 2006) which argues that individuals adjust their aspirations to reflect what is available to them (Nussbaum, 1999). Capability theorists, however, argue that just because someone has come to expect specific treatment does not mean that they are not entitled to more and that their feelings should not be considered when thinking about capabilities and functionings that would constitute a good life for them (Begon, 2015). This belief is thought to further alienate marginalized and oppressed groups because their preferences are characterized as "unreliable, and those who hold them as irrational and "defective agents"” (Begon, 2015, p. 242).

When it comes to adaptive preferences, the oppressive history and current living conditions of many individuals in South Africa may indicate that inclusion is not something that they aspire to because it has not been available to them previously. With regards to parents specifically, many have been excluded as a result of apartheid and its ongoing legacy. They therefore continue to see and experience exclusion and may, in fact, not believe that inclusion is possible; therefore, it is not an expectation. This belief that inclusion is not possible may be externalized, which results in parents inadvertently acting against inclusion. This adaptive preference affects an individual's freedom, resulting in an individual not having the freedom to pursue inclusion.

All aspects of the CA, however, cannot be applied fully to all spheres of society. Children, in particular, cannot exercise their freedom and agency in its entirety, due to their dependency on adults. Education is one such element of a child's life. CA acknowledges that education plays a role in developing children's capabilities through the expansion of both ability and opportunity while also improving well-being, freedom, and achievement (Terzi, 2005). However, given that children are dependent on the adults responsible for them, their freedom and agency are limited. In South Africa, children between the ages of seven and 15 are required by law to attend school (Republic of South Africa, 1996). Consequently, their freedom (i.e. not to attend school) in this regard is restricted. Conversely, some parents may choose not to send their children to school, possibly due to financial reasons, despite the child's desire to attend school. It is the freedoms, agency, capabilities, functionings, and values of the adult, who is required to protect the children's interests and meet their needs (Terzi, 2005), that impact on the child's freedoms and agency. With regard to the successful implementation of inclusion, this demonstrates the value in shifting the focus from the child to those responsible for implementing inclusion.

An additional criticism against the $\mathrm{CA}$ has been that it is too individualistic and, as a result, does not pay attention to groups (Robeyns, 2005). An argument against this criticism, however, is that the CA embraces ethical individualism, which refers to the notion that individuals "are the units of moral concern" (Robeyns, 2005, p. 107). With a focus on ethical individualism, CA is concerned with the impact of social structures on the individual (Robeyns, 2005), as can be seen with the impact of social and environmental conversion factors on the acquisition of functionings. Deneulin and McGregor (2010, p. 514) also highlight the shortcomings of the approach in relation to the "social and political nature of human well-being" noting that gains for some may be losses for others. This is a perception held by some parents in relation to the inclusion of children with barriers to learning, perceiving that the inclusion of children with barriers is a loss for their children without barriers in relation to teacher time and attention (Kern, 2020).

As has been demonstrated, both BET and the CA have aspects to offer in understanding the challenges facing inclusion; however, both also have gaps in their understanding. Consequently, an integration of the two theories offers a conceptual framework in which the 


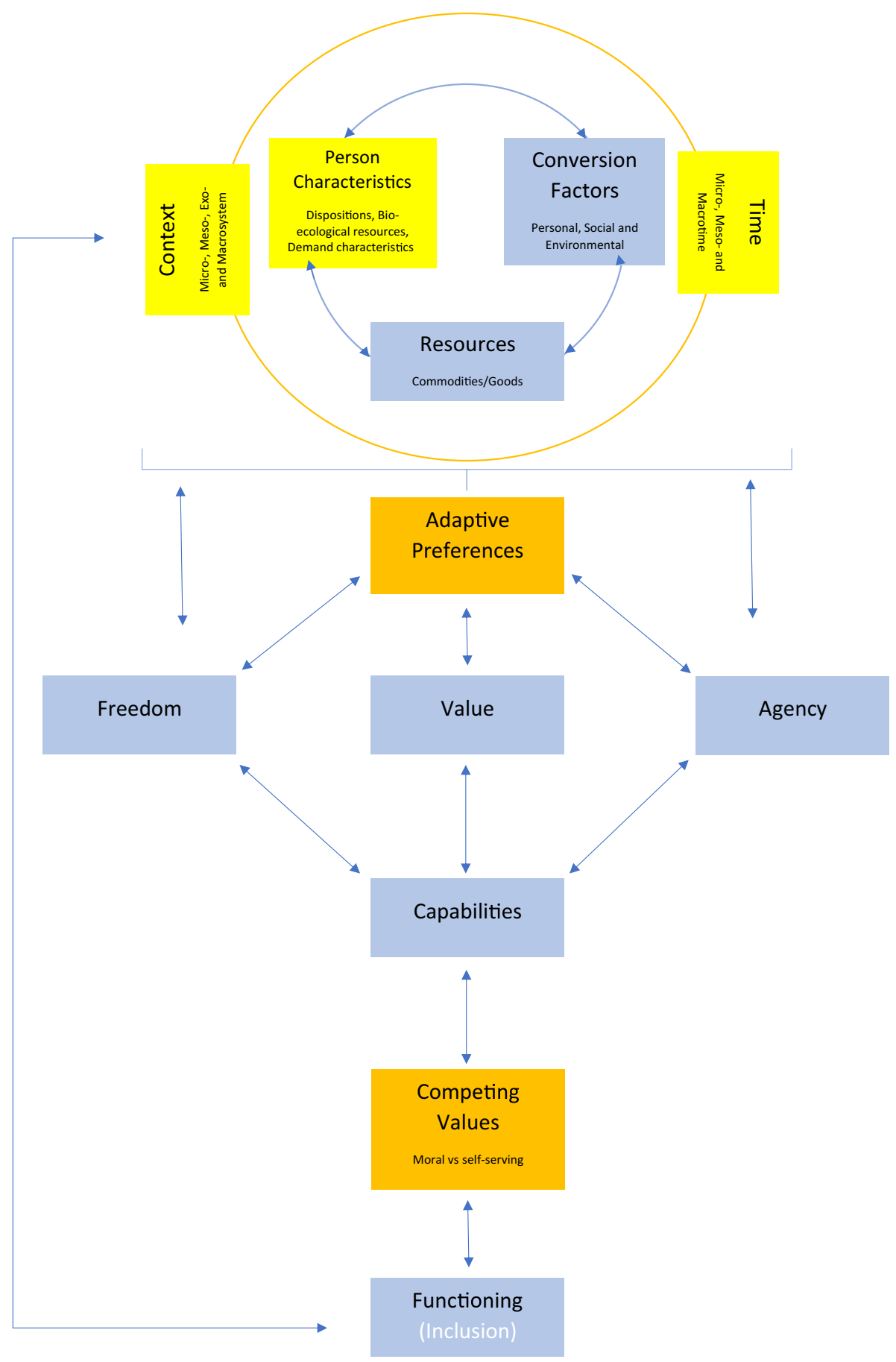

Figure 3 Combination of the bio-ecological theory and the capability approach 
limitations of both are addressed and the identified strengths are used to offer a more holistic understanding of the challenges facing inclusion from an individual perspective (Fig. 3).

\section{Reconceptualized understanding of factors affecting inclusion}

While there are numerous challenges facing the implementation of inclusion in South Africa, one such challenge relates to the individual role-players within inclusion, with the DoBE (2015) stating that managers and teachers are unable to support the learning needs of all children. This challenge relates to a lack of knowledge, commonly held stereotypes, and cultural beliefs, among others. An understanding of the challenges to implementing inclusion is difficult to obtain without considering the cultural-historical contexts and lived realities of the community as argued by Engelbrecht (2020, p. 8). This idea is further supported by Singal and Muthukrishna (2014, p. 300) who assert that "it is only when we truly begin to develop deeper appreciation of the context and make efforts to understand individual and collective stories that we can open up the moral and political space for effective education reform efforts". The conceptual framework presented in Figure 3 aims to consider the cultural and historical contexts while exploring the factors that affect an individual's ability to be inclusive. Consequently, an amalgamation of BET and the CA appears best suited to explain some of the challenges facing inclusion in South Africa on an individual level. The concepts used in the framework therefore mirror the meaning reflected on the original work of the theorists.

If one considers "being inclusive" as a functioning, a way of being, then the framework aims to understand the factors that support or hinder an individual's development of this functioning. The framework conceptualizes "being inclusive" (functioning) as a desired end, with a discussion of how the interaction between the various factors drawn from BET and the CA act as a means to the end.

The framework starts with a representation of the bi-directional interaction between the person characteristics (BET), resources (CA), and conversion factors (CA) within the space of context (BET) and time (BET). According to BET, a person comprises person characteristics that determine the way an individual responds to the world (context) and how the world responds to the individual (Bronfenbrenner \& Morris, 2007). For inclusion, an understanding of the person characteristics offers insight into how the person relates to, for example, children, teachers, district officials, and trainers, given that person characteristics influence a person's ability to engage with others while simultaneously encouraging or discouraging interactions from those around them. The EWP6 (DoE, 2001, p. 50) states that partnerships between parents and the institution should be developed so that they can be "armed with information, counselling and skills, participate more effectively in the planning and implementation of inclusion activities, and so that they can play a more active role in the learning and teaching of their own children, despite limitations due to disabilities or chronic illnesses". The person characteristics of the parents and teachers will therefore determine the extent to which these partnerships flourish or deteriorate.

Person characteristics interact with resources, also referred to as goods or commodities by Robeyns (2005), that are available to an individual. Resources are important to development because they provide an individual with an opportunity to do something with them (Deneulin \& McGregor, 2010). However, what a person can do with a resource is determined by conversion factors (personal, social, and environmental) and person characteristics. For example, a parent may be provided with a booklet regarding inclusion and its benefits. However, if the parent is illiterate (person characteristic), their personal conversion 
factors will impact on their ability to use the resource (information booklet) to gain knowledge. In another instance, the parent may be able to read, understand, and integrate the information gained from the booklet (resource); however, their ability to action that information may be impacted by societal and cultural stereotypes (conversion factors).

Given that barriers to learning arise from a multitude of mostly socioeconomic factors, conversion factors are important in understanding an individual's motivation to attain the functioning of being inclusive. These conversion factors affect the implementation of inclusion as, while policy determines that a child with barriers to learning should attend their neighbourhood school, the social conversion factors (e.g., attitude of the community) or the environmental conversion factors (e.g., school without ramps) will mean that the child is unable to access the school. An example of the impact that the environment has on the implementation of inclusion was found by Engelbrecht (2020) where teachers who demonstrated a commitment and motivation to teach inclusively were hindered by the leadership in their specific schools. Thus, their personal characteristics were impacted by the environmental conversion factors.

The development of personal characteristics, conversion factors, and resources occur over time within specific contexts. Time specifically relates to micro-time, meso-time, and macro-time. In South Africa, the impact of macro-time in conjunction with the macro-system cannot be overstated. The system of apartheid is a historical event that would be captured in the macro-system; however, its impact is seen across macro-time. The impact of this system is seen in the person characteristics, conversion factors, and resources available to an individual. The disparate education system emerging during apartheid resulted in the emergence of inclusion within the macro-system post-apartheid. However, the effect of the apartheid system is that many adults in present-day South Africa may be hindered by a mindset (person characteristic) which may result in adaptive preferences that are, in fact, in opposition to inclusion. Similarly, teachers' lack of initial teacher training with regards to inclusion may make them feel that they are unable to teach within an inclusive environment (Engelbrecht, 2020; Seedat, 2018).

Adaptive preferences are what individuals come to expect for themselves given the context that they find themselves in and the impact of events over time (Begon, 2015; Otto \& Ziegler, 2006). Adaptive preferences will consequently influence what a person comes to value, their agency, and their freedom to act. Thus, an individual who has lived a life of discrimination may continue to expect it from the environment and may act in a way to perpetuate discrimination. Given their experiences, teachers too may have difficulties with implementing inclusion, perhaps due to a lack of resources or overcrowding, and may consider inclusion too difficult to implement (Engelbrecht, 2020). In both of these examples, parents and teachers may continue to exclude children with barriers to learning believing that inclusion is, in fact, not possible.

Value, agency, and freedom (CA), having been impacted by adaptive preferences, in conjunction with context and time, will determine the capabilities that a person develops. This implies that what the person has come to value, along with their freedom to choose and act, will impact the potential beings and doings that the individual develops. The individual then determines which capabilities they convert into functionings. However, what functioning is realized may be influenced by competing values. For example, parents in South Africa value education and inclusion (Kern, 2020); however, these are sometimes seen to be competing functionings because inclusion, while valued, is viewed as a hindrance to a quality education. As a result, in an endeavour to provide their children with quality education, parents may choose to exclude those who they view as interfering with 
their children's education. Being educated is thus chosen as a functioning at the expense of being inclusive.

\section{Conclusion}

According to the DoBE (2018), the main aim of an inclusive education system is to ensure that all children have access to an inclusive quality education on an equal basis with their peers in the community. This is achieved through the support of children irrespective of their background, culture, language, ability, or disability. Consequently, research into inclusion usually has at its center the child who should be included and the criteria that would be met for inclusion to occur successfully (Engelbrecht, 2020). However, this paper argues that a focus on the child overlooks an important determinant of inclusion, which is that the adults are responsible for implementing inclusion.

Inclusion, a social-justice issue, has at its core a respect for the diversity of individuals (DoE, 2001, 2020). By applying this statement to the adults regarded as integral to the successful implementation of inclusion, the conceptual framework presented is used to obtain an in-depth understanding of the person, allowing insight into factors that hinder or support their move toward inclusion. By placing an emphasis on heterogeneity, the conceptual framework moves away from the predominant second discourse of inclusion, which ultimately focuses on the inclusion of specific groups of people, to the third discourse with educational theory and practice as the focal point.

Gaining an understanding of the individual using the conceptual framework presented would allow a more nuanced approach to the strategy the DoE will use to win the support of role-players, and the training and support needs to be offered before "rights, responsibilities and obligations" (DoE, 2001, p. 33) are thrust upon them. In so doing, support for the policy of inclusion may increase thereby increasing the likelihood of its successful implementation (Du Plessis, 2013).

Open Access This article is licensed under a Creative Commons Attribution 4.0 International License, which permits use, sharing, adaptation, distribution, and reproduction in any medium or format, as long as you give appropriate credit to the original author(s) and the source, provide a link to the Creative Commons licence, and indicate if changes were made. The images or other third-party material in this article are included in the article's Creative Commons licence, unless indicated otherwise in a credit line to the material. If material is not included in the article's Creative Commons licence and your intended use is not permitted by statutory regulation or exceeds the permitted use, you will need to obtain permission directly from the copyright holder. To view a copy of this licence, visit http://creativecommons.org/licenses/by/4.0/

\section{References}

Abery, B., Tichá, R., \& Kincade, L. (2017). Moving toward an inclusive education system: Lessons from the US and their potential application in the Czech Republic and other Central and Eastern European countries. Social Education, 5(1), 48-62.

Allan, J. (2005). Encounters with exclusion through disability arts. Jorsen: Journal of Research in Special Education Needs, 5(1), 31-36.

Anderson, J., Boyle, C., \& Deppeler, J. (2014). The ecology of inclusive education: Reconceptualising Bronfenbrenner. In H. Zhang, P. Chan, \& C. Boyle (Eds.), Equality in education: Fairness and inclusion (pp. 23-34). Sense Publishers.

Andrews, D., Walton, E., \& Osman, R. (2019). Constraints to the implementation of inclusive teaching: A cultural historical activity theory approach. International Journal of Inclusive Education. https://doi. org/10.1080/13603116.2019.1620880 
Artiles, A. J., Kozleski, E. B., Dorn, S., \& Christensen, C. (2006). Learning in inclusive education research: Re-mediating theory and methods with a transformative agenda. Review of Research in Education, $30(1), 65-108$.

Begon, J. (2015). What are adaptive preferences? Exclusion and disability in the capability approach. Journal of Applied Philosophy, 32(3), 241-257.

Brantlinger, E. (2003). Dividing classes. Routledge.

Bronfenbrenner, U. (1977). Toward an experimental ecology of human development. American Psychologist, 32(7), 513-531.

Bronfenbrenner, U., \& Evans, G. W. (2000). Developmental science in the 21 st century: Emerging questions, theoretical models, research designs and empirical findings. Social Development, 9(1), 115-125.

Bronfenbrenner, U., \& Morris, P. A. (2007). The bioecological model of human development. In W. Damon \& R. M. Lerner (Eds.), Handbook of child psychology, vol. I: Theoretical models of human development (6th ed., pp. 793-828). Wiley.

Claassen, R. (2014). Human dignity in the capability approach. In R. Claassen (Ed.), The Cambridge handbook of human dignity (pp. 240-249). Cambridge University Press.

Crocker, D. A., \& Robeyns, I. (2010). Capability and agency. In C. Morris (Ed.), Amartya Sen (pp. 60-90). Cambridge University Press.

Dalkilic, M., \& Vadeboncoeur, J. A. (2016). Re-framing inclusive education through the capability approach: An elaboration of the model of relational inclusion. Global Education Review, 3(3), 122-137.

Dalton, E. M., Mckenzie, J. A., \& Kahonde, C. (2012). The implementation of inclusive education in South Africa: Reflections arising from a workshop for teachers and therapists to introduce Universal Design for Learning. African Journal of Disability, 1(1), 13.

Davison, A., \& Scholl, K. (2017). Inclusive recreation as part of the IEP process. In C. Curran \& A. Peterson (Eds.), Handbook of research on classroom diversity and inclusive education practice (pp. 311330). IGI Global.

De Boer, A., Pijl, S. J., \& Minnaert, A. (2011). Regular primary schoolteachers' attitudes towards inclusive education: A review of the literature. International Journal of Inclusive Education, 15(3), 331-353.

Deneulin, S., \& McGregor, J. (2010). The capability approach and the politics of social wellbeing. European Journal of Social Wellbeing, 13(4), 501-519.

DoBE [Department of Basic Education, South Africa]. (2014). Draft policy on screening, identification, assessment and support. Government Printers. www.gov.za/sites/default/files/gcis_document/201409/ sias-revised-final-comment.pdf

DoBE. (2015). Report on the implementation of Education White Paper 6 on inclusive education: An overview for the period 2013-2015. Government Printers.

DoBE. (2018). Draft national guidelines for an inclusive education system. Government Printers.

DoE [Department of Education, South Africa]. (2001). Education White Paper 6. Special needs education: Building an inclusive education and training system. Government Printers.

DoE [Department of Education, South Africa]. (2020). Thuthong. Department of Education. www.thutong. doe.gov.za/inclusiveeducation/InclusiveEducation/tabid/1341/Default.aspx

Donohue, D., \& Bornman, J. (2014). The challenges of realising inclusive education in South Africa. South African Journal of Education, 34(2), 1-14.

Du Plessis, P. (2013). Legislation and policies: Progress towards the right to inclusive education. De Jure Law Journal, 46(1), 76-92.

Engelbrecht, P. (2006). The implementation of inclusive education in South Africa after ten years of democracy. European Journal of Psychology of Education, 21(3), 253.

Engelbrecht, P. (2020). Inclusive education: Developments and challenges in South Africa. Prospects, 49(34), 219-232.

Engelbrecht, P., \& Muthukrishna, N. (2019). Inclusive education as a localised project in complex contexts: A South African case study. Southern African Review of Education, 25(1), 107-124.

Göransson, K., \& Nilholm, C. (2014). Conceptual diversities and empirical shortcomings: A critical analysis of research on inclusive education. European Journal of Special Needs Education, 29(3), 265-280.

Hackett, J. D., Hudson, R. F., West, E. A., \& Brown, S. E. (2016). Cambodian inclusive education for vulnerable populations: Toward an ecological perspective policy. Journal of International Special Needs Education, 19(1), 3-14.

Houston, S. (2017). Towards a critical ecology of child development in social work: Aligning the theories of Bronfenbrenner and Bourdieu. Families, Relationships and Societies, 6(1), 53-69.

Kamenopoulou, L. (2016). Ecological systems theory: A valuable framework for research on inclusion and special educational needs/disabilities. Pedagogy: Bulgarian Journal of Educational Research and Practice, 88(4), 515-527. 
Kern, A. C. (2020). South African parents' understanding of inclusion and exclusion in education in primary schools. Perspectives in Education, 38(2), 255-271.

Landsberg, E., Krüger, D., \& Nel, N. (2005). Addressing barriers to learning: A South African perspective. Van Schaik.

Lui, M., Sin, K., Yang, L., Forlin, C., \& Ho, F. (2015). Knowledge and perceived social norm predict parents' attitudes towards inclusive education. International Journal of Inclusive Education, 19(10), 1052-1067.

Nussbaum, M. C. (1999). Sex and social justice. Oxford University Press.

Okkolin, M. A., Koskela, T., Engelbrecht, P., \& Savolainen, H. (2018). Capability to be educated: Inspiring and inclusive pedagogical arrangements from Finnish schools. Journal of Human Development and Capabilities, 19(4), 421-437.

Otto, H. U., \& Ziegler, H. (2006). Capabilities and education. Social Work \& Society, 4(2), 269-287.

Phasha, N., Mahlo, D., \& Dei, G. J. S. (Eds.) (2017). Inclusive education in African contexts: A critical reader. Sense Publishers.

Potgieter-Groot, L., Visser, M., \& Lubbe-de Beer, C. (2012). Emotional and behavioural barriers to learning and development in the inclusive education classrooms in South Africa: Developing a training programme for teachers. Journal of Child and Adolescent Mental Health, 24(1), 59-71.

Reindal, S. (2016). Discussing inclusive education: An inquiry into different interpretations and a search for ethical aspects of inclusion using capabilities approach. European Journal of Special Needs Education, 31(1), 1-12.

Republic of South Africa. (1996). South African Schools Act 84 of 1996. Government Printers.

Robeyns, I. (2005). The capability approach: A theoretical survey. Journal of Human Development, 6(1), 93-117.

Rosa, E. M., \& Tudge, J. (2013). Urie Bronfenbrenner's theory of human development: Its evolution from ecology to bioecology. Journal of Family Theory \& Review, 5(4), 243-258.

Sayed, Y., \& Motala, S. (2012). Equity and "no fee" schools in South Africa: Challenges and prospects. Social Policy and Administration, 46(6), 672-687.

Seedat, N. (2018). A thematic review of inclusive education research in South Africa. Doctoral dissertation, Wits University. https://wiredspace.wits.ac.za/handle/10539/26023

Sen, A. (1999). Development as freedom. Oxford University Press.

Singal, N., \& Muthukrishna, N. (2014). Education, childhood and disability in countries of the South: Re-positioning the debates. Childhood, 21(3), 293-307.

Singh, P., \& Mbokodi, S. M. (2011). Parental partnerships in the governance of schools in the Black townships of Port Elizabeth. Perspectives in Education, 29(4), 38-48.

Slee, R. (2011). The irregular school: Exclusion, schooling and inclusive education. Routledge.

Smit, S., Preston, L. D., \& Hay, J. (2020). The development of education for learners with diverse learning needs in the South African context: A bio-ecological systems analysis. African Journal of Disability, 9(1), 1-9.

Swart, E., \& Pettipher, R. (2016). A framework for understanding inclusion. In E. Landsberg (Ed.), Addressing barriers to learning: A South African perspective (pp. 3-23). Van Schaik.

Terzi, L. (2005). A capability perspective on impairment, disability and special needs: Towards social justice in education. Theory and Research in Education, 3(2), 197-223.

Themane, M., \& Thobejane, H. R. (2018). Teachers as change agents in making teaching inclusive in some selected rural schools of Limpopo Province, South Africa: Implications for teacher education. International Journal of Inclusive Education, 23(4), 369-383.

Thomazet, S. (2009). From integration to inclusive education: Does changing the terms improve practice? International Journal of Inclusive Education, 13(6), 553-563.

Tikly, L., \& Barrett, A. (2011). Social justice, capabilities and the quality of education in low income countries. International Journal of Educational Development, 31(1), 3-14.

Trani, J. F., Bakhshi, P., Bellanca, N., Biggeri, M., \& Marchetta, F. (2011). Disabilities through the capability approach lens: Implications for public policies. Alter, 5(3), 143-157.

UNESCO. (1994). The Salamanca statement and framework for action on special needs education. UNESCO.

Unterhalter, E. (2009). What is equity in education? Reflections from the capability approach. Studies in Philosophy and Education, 28(5), 415-424.

Vélez-Agosto, N. M., Soto-Crespo, J. G., Vizcarrondo-Oppenheimer, M., Vega-Molina, S., \& García Coll, C. (2017). Bronfenbrenner's bioecological theory revision: Moving culture from the macro into the micro. Perspectives on Psychological Science, 12(5), 900-910.

Walker, M. (2012). A capital or capabilities education narrative in a world of staggering inequalities. International Journal of Educational Development, 32(3), 384-393. 
WHO [World Health Organization]. (2011). World report on disability.

Wrigley, T., Thomson, P., \& Lingard, B. (2012). Reimagining school change: The necessity and reasons for hope. In T. Wrigley, P. Thomson, \& B. Lingard (Eds.), Changing schools: Alternative ways to make a world of difference (pp. 17-30). Routledge.

Xiao, Y., \& Watson, M. (2019). Guidance on conducting a systematic literature review. Journal of Planning Education and Research, 39(1), 93-112.

Yssel, N., Engelbrecht, P., Oswald, M. M., Eloff, I., \& Swart, E. (2007). Views of inclusion: A comparative study of parents' perceptions in South Africa and the United States. Remedial and Special Education, $28(6), 356-365$.

Publisher's Note Springer Nature remains neutral with regard to jurisdictional claims in published maps and institutional affiliations.

Anwynne Kern is a registered educational psychologist and psychology lecturer in the Department of Psychology, School of Human and Community Development (SHCD) at the University of the Witwatersrand. Prior to becoming part of the psychology community, Anwynne taught at two primary schools for six years. It was there that her understanding of the complexity of development and teaching and learning continued to develop. She completed her Bachelor of Education with Honours (BEd) and Master's in Education (Educational Psychology). Anwynne's teaching experience and interactions with children and parents gave rise to her research interests which center on inclusion in education, for which she has received scholarships. 